\title{
The Earlier Wittgenstein on the Notion of Religious Attitude
}

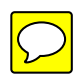

\author{
Chon Tejedor
}

\begin{abstract}
:
I defend a new interpretation of Wittgenstein's notion of religious (or ethical) attitude in the Tractatus, one that rejects three key views from the secondary literature: firstly, the view that, for Wittgenstein, the willing subject is a transcendental condition for the religious attitude; secondly, the view that the religious attitude is an emotive response to the world or something closely modelled on this notion of emotive response; and thirdly, the view that, although the religious and ethical pseudo-propositions of the Tractatus are nonsensical, they nevertheless succeed in expressing the religious attitude endorsed by Wittgenstein. In connection to the first, I argue that the notion of willing subject as transcendental condition is abandoned by Wittgenstein in the Notebooks and is no longer a feature of his position in the Tractatus. In connection to the second, I argue that the religious attitude is dispositional rather than emotive for Wittgenstein: it is a disposition to use signs in a way that demonstrates one's conceptual clarity. Finally, in connection to the third, I argue that the religious or ethical attitude is strongly ineffable in that it cannot be described, expressed or conveyed by language at all.
\end{abstract}




\section{$\underline{\text { Introduction }}$}

In this paper, I defend a new interpretation of Wittgenstein's notion of religious attitude in the Tractatus. For Wittgenstein, religiousness is closely intertwined with ethical considerations, especially during this period. ${ }^{1}$ In fact, Wittgenstein's earlier approach to religion cannot be easily extricated from his approach to ethics and the former is most effectively explored in connection to the latter. For this reason, I will, in this paper, be drawing on remarks from the Notebooks, the Prototractatus, the Tractatus and 'A Lecture on Ethics' that are sometimes described in the secondary literature as focusing on religion and sometimes on ethics..$^{2}$ I myself will be using the expression 'religious attitude' to capture Wittgenstein's notion of an ethically correct or genuinely religious attitude. $^{3}$

Part of my aim in this paper is to argue against three views from the secondary literature that have, I contend, had a distorting effect on our understanding of

\footnotetext{
$1 \quad$ Joachim Schulte notes: 'for Wittgenstein genuine religiousness is always connected with decisions on how to lead a decent life. One might say that his view of religion was a profoundly ethical one' Schulte, J. 'On a Remark by Jukundus', Synthese Library \#346: Interactive Wittgenstein: Essays in Memory of Georg Henrik Von Wright, E. De Pellegrin (ed.), (Springer, 2011) 183-208, 186. Severin Schroeder explains that, even in his later philosophical period, Wittgenstein's interest was primarily with a notion of religion 'that he personally found appealing: comprehensible, intellectually respectable and morally attractive' - Schroeder, S. 'The Tightrope Walker', Ratio 20, 4, (2007) 442-463, 444

2 References are drawn from: Wittgenstein, L. Notebooks 1914-1916 (NB), eds. G. von Wright and G. E. M. Anscombe, transl. G. E. M. Anscombe, (Oxford: Blackwell, 1961); Wittgenstein, L. Prototractatus (PTLP), eds. B. F. McGuinness, T. Nyberg \& G. von Wright, transl. B. F. McGuinness \& D. F. Pears (London: Routledge, 1971); Wittgenstein, L. Tractatus Logico-Philosophicus (TLP), transl. D.F. Pears and B.F. McGuinness, (London: Routledge, 1961); Wittgenstein, L. 'A Lecture on Ethics' (LOE), The Philosophical Review, 74, 1, 3-12 (1965). Although ten years separate the writing of the Tractatus and that of 'A Lecture on Ethics', Wittgenstein's approach to religiousness and the ethical remains so close in these two texts that they are, in my view, best examined alongside each other.

3 Here, I favour the expressions 'religious attitude' and 'religiousness' because I feel they better capture Wittgenstein's idiosyncratic understanding of the ethical, which is quite distant from our contemporary conceptions of ethics.
} 
Wittgenstein's position on religion in the Tractatus. The views in question can be characterised as follows:

1. Religiousness (ethics) is transcendental in that the willing subject is a transcendental condition of the religious attitude. ${ }^{4}$

2. The religious attitude is to be understood as an emotive response to the world or, at the very least, as something closely modelled on this notion of emotive response. $^{5}$

3. Although the religious and ethical pseudo-propositions of the Tractatus (i.e. the TLP 6.4ff) are nonsensical, they succeed in conveying or expressing the religious attitude that Wittgenstein endorses. ${ }^{6}$

I propose that we misrepresent Wittgenstein's position when we ascribe these views to him in the Tractatus. Although Wittgenstein may well have endorsed some or all of these views, at least to an extent, in the Notebooks period, he has in fact abandoned them by the time he comes to write the Tractatus. These views are not therefore representative of his position in the Tractatus.

$4 \quad$ Different versions of this view appear in: Morris, M. Routledge Philosophy Guidebook to Wittgenstein and the Tractatus Logico-Philosophicus, (New York: Routledge, 2008) 320-328; Schroeder, S. Wittgenstein: The Way Out of the Fly-Bottle, (Cambridge: Polity, 2006) 99-104; and Stockhof, M. World and Life as One. Ethics and Ontology in Wittgenstein's Early Thought. (Palo Alto: Standford University Press, 2002), 202-203.

5 Different versions of this view emerge in Morris op. cit. note 4, 324 and McGuinness, B. Approaches to Wittgenstein: Collected Papers, (London: Routledge, 2002) 141, amongst others.

6 Different versions of this view emerge in Stokhof op. cit. note 4 and in Morris op. cit. note 4, 337338. 


\section{$\underline{1 .}$ Religion without a Transcendental Subject}

\section{a) The Transcendental Reading}

According to a widespread reading, which I will call the Transcendental Reading, Wittgenstein endorses, in the Tractatus, the notion of a transcendental subject as the condition of genuine religiousness (ethics) and - depending on the reading representation. ${ }^{7}$ Wittgenstein certainly appears to endorse this notion of the subject which he calls 'willing subject' - at several junctures in the Notebooks ( $\underline{N B}$ 5.8.16). In the Transcendental Reading, this notion of 'willing subject' is retained in the Tractatus and, with it, the idea that genuinely ethical religiousness is transcendental: religiousness is transcendental in that the religious attitude is made possible by virtue of the actions of the transcendental willing subject. According to the Transcendental Reading, it is in this light that we should interpret Wittgenstein's claim, in the Tractatus, that:

Ethics is transcendental. (TLP 6.421)

b) The transcendental 'willing subject'

\footnotetext{
7 See, for instance: Morris op. cit. note 4 320-328; Schroeder op. cit. note 4, 99-104; and Stokhof op. cit. note 4, 202-203. Peter Hacker places the emphasis on the view that the willing subject is the condition of representation - Hacker, P. M. S. Insight and Illusion. Themes in the Philosophy of Wittgenstein (Oxford: Oxford University Press, 1986), 73-80.
} 
One immediate problem with the Transcendental Reading is that the expression 'willing subject' is simply absent from the Tractatus. The closest that Wittgenstein comes to this notion in the Tractatus is in TLP 6.423, where he writes:

It is impossible to speak about the will in so far as it is the subject of ethical attributes. (TLP 6.423)

However, even if we took this remark at face value as an attempt to convey something about the ethical will (which is problematic, as we will see below), it is highly unclear that it would provide evidence for the view that Wittgenstein continues to endorse, in the Tractatus, the notion of a willing subject. We could, instead, take this remark to show that Wittgenstein has shifted from the reified notion of a transcendental willing subject in the Notebooks to a deflated notion of ethical willing in the Tractatus. Similarly, it could be argued that Wittgenstein's understanding of the way in which 'ethics is transcendental' (TLP 6.421) has itself become deflated in the move from the Notebooks to the Tractatus: Wittgenstein would have shifted from the Notebooks view that the willing subject is a transcendental condition of ethics to the deflated view that ethics is transcendental merely in that ethical willing is ineffable. Regardless of how one views the merits or demerits of such proposals, it seems clear that entries such as TLP 6.423 and TLP 6.421 cannot, on their own, be regarded as conclusive evidence for the view that Wittgenstein continues to endorse, in the Tractatus, the notion of willing subject from the Notebooks. 


\section{c) The 'metaphysical subject'}

At this point, it might be objected that, in fact, the evidence is not quite as slim as that. For perhaps Wittgenstein does retain the notion of 'willing subject' in the Tractatus, only under a different label: 'metaphysical subject'. After all, Wittgenstein does use the expression 'metaphysical subject' in the Tractatus. Indeed, he appears actively to endorse it in TLP 5.641:

Thus there really is a sense in which philosophy can talk about the self in a nonpsychological way.

What brings the self into philosophy is the fact that 'the world is my world'.

The philosophical self is not the human being, not the human body, or the human soul, with which psychology deals, but rather the metaphysical subject, the limit of the world - not a part of it. (TLP 5.641)

The question before us is therefore: could the 'metaphysical subject' of TLP 5.641 be the willing subject of the Notebooks? In other words, is the 'metaphysical subject' of $\underline{T L P}$ 5.641 regarded by Wittgenstein as a transcendental pre-condition of ethics? There are some serious problems with this suggestion. To begin with, there is simply no evidence, in the Notebooks, to suggest that Wittgenstein regards the expressions 'willing subject' and 'metaphysical subject' to be interchangeable. Both expressions appear in the Notebooks, but - crucially - they are never used alongside each other in the same entries. ${ }^{8}$

\footnotetext{
8 Indeed, the expression 'metaphysical subject' is only used in two entries of the Notebooks: in $N B$ 4.8.16 and in $N B$ 2.9.16.
} 
And there is nothing in the entries that do feature them (i.e. that do so separately) to suggest that Wittgenstein views these expressions as equivalent. In other words, there is nothing in the Notebooks to suggest that 'metaphysical subject' is synonymous with, or even analogous to, 'willing subject' for Wittgenstein.

But there is a second and more fundamental problem with arguing that the metaphysical subject of TLP 5.641 is the willing subject of the Notebooks. For TLP 5.641 starts off by noting that 'there really is a sense in which philosophy can talk about' the metaphysical subject. In the original, this reads: 'Es gibt also wirklich einen Sinn, in welchem in der Philosophie nicht-psychologisch vom Ich die Rede sein kann.' The mention of 'die Rede' in the original makes it clear that Wittgenstein's claim is that it is possible to speak about the metaphysical subject. What is more, Wittgenstein appears to be suggesting that one of the tasks of philosophy is to continue talking about such a subject. If the metaphysical subject were the willing subject from the Notebooks, however, this would be deeply puzzling, however. For Wittgenstein would be advancing that the willing subject is a transcendental condition of the world (a limit in this sense), that the willing subject can be talked about, and that philosophers should continue talking about it. But such a position would surely be untenable for Wittgenstein: if the metaphysical subject were indeed the willing subject from the Notebooks, Wittgenstein should, at the very least, admit, in TLP 5.641, that the metaphysical subject cannot be talked about. The claim that the metaphysical subject 'really' ('wirklich') can be talked about, especially in conjunction with the suggestion that it is one of the tasks of philosophy to talk about such a subject, is totally mysterious if we understand 'metaphysical subject' to be referring to the willing subject from the Notebooks. After all, 
there is nothing in the sections of the Tractatus in which Wittgenstein discusses the role of philosophy (notably TLP 4.112, 4.114, 4.115, 4.116 and the Preface) to suggest that the task of philosophy should be to attempt to say or even to express what cannot be said. Independently of the position one may occupy in the New Wittgenstein debate, it is clear that there is a serious problem with this idea; this is indeed acknowledged by a variety of authors, many of whom could in no way be classed as neo-Wittgensteinians. ${ }^{9}$

\section{d) A shift in Wittgenstein's position}

The evidence for the claim that the 'willing subject' from the Notebooks is the 'metaphysical subject' is, in my view, virtually non-existent; in fact, as we have just seen, this claim runs counter the textual evidence from TLP 5.641 and other sections of the Tractatus. There is, in addition, one further set of considerations that arbitrates against this claim. Note indeed that, having endorsed the notion of willing subject in entries such as $N B$ 5.8.16, the Notebooks discussion comes to a rather abrupt end in November of 1916, with two entries that show Wittgenstein as having second thoughts about this notion: $N B$ 9.11.16 and $N B$ 19.11.16. $\underline{N B}$ 9.11.16 indicates that experience does not require the willing subject to be possible. Since experience is a type of thought, of mental representation (or picture) for Wittgenstein, $\underline{N B}$ 9.11.16 therefore advances that mental representation does not require the willing subject. In the next entry (i.e. $\underline{N B}$ 19.11.16), Wittgenstein considers an even stronger suggestion: the suggestion that there may in fact

\footnotetext{
9 Bernard Williams mentions this difficulty in Williams, B. 'Wittgenstein and Idealism', Moral Luck: Philosophical Papers 1973-1980, (Cambridge: Cambridge University Press, 1981), 144-163, 146. David Pears also admits that this is a serious problem - Pears. D. The False Prison, Vol. 1, (Oxford: Clarendon Press, 1987) 184-185.
} 
be no reason whatsoever to posit a willing subject. In other words, in $\underline{N B}$ 19.11.16, Wittgenstein is considering abandoning the notion of willing subject in its entirety: he is considering abandoning the notion of a transcendental subject understood as a condition of representation or of ethics. I propose that Wittgenstein does indeed end up abandoning this notion in or shortly after November 1916 - and certainly before he starts working on the final version of the Tractatus.

That Wittgenstein's approach to ethics and religion undergoes a significant change precisely around this time is corroborated by his correspondence with Paul Engelmann. Wittgenstein's thoughts about the willing subject develop most rapidly during the weeks he spends with Engelmann, whom he meets in Olmütz in October 1916. ${ }^{10}$ We know that many of the conversations between Wittgenstein and Engelmann during this period focus on Schopenhauer's approach to ethics, an approach that posits a transcendental notion of the subject very much like that of the 'willing subject' from the Notebooks. ${ }^{11}$ The strongly Schopenhauerian remarks from the Notebooks end abruptly in late November 1916, with the two entries I mentioned above ( $N B$ 9.11.16 and $N B$ 19.11.16). Shortly thereafter, Wittgenstein leaves Olmütz to travel to Vienna for Christmas and then returns to the front. By the time Engelmann and Wittgenstein meet again in December 1917, it is clear to Engelmann that Wittgenstein has had an important change of heart. In January 1918, Engelmann writes a letter in which he expresses his concern over Wittgenstein's religious condition. Referring to their recent meeting, in December 1917, Engelmann writes:

\footnotetext{
$10 \quad$ See $N B$ 12.10.16; 15.10.16; 17.10.16; 20.10.16; 4.11.16; 9.11.16; and 19.11.16

11 That Wittgenstein and Engelmann repeatedly discuss Schopenhauer's views during their stay in Olmütz emerges in McGuinness, B. Wittgenstein: A Life. Young Ludwig 1889-1921 (New York: Oxford University Press, 2005), $252-253$.
} 
It seemed to me as if you - in contrast to the time you spent in Olmütz, where I had not thought so - had no faith.

To this, Wittgenstein replies:

If you tell me I have no faith, you are perfectly right, only I did not have it before either. [...] I am clear about one thing: I am far too bad to be able to theorize about myself; in fact, I shall either remain a swine or else I shall improve, and that's that! Only let's cut out the transcendental twaddle when the whole thing is as plain as a sock on the jaw. [My italics in the last instance] ${ }^{12}$

Wittgenstein's reply to Engelmann betrays an important change in Wittgenstein's attitude to (and tolerance of) the transcendental approach to religion and ethics that had been the focus of so many of his conversations with Engelmann in Olmütz, in the autumn of 1916. A likely explanation for this change would be that, having explored the Schopenhauerian, transcendental approach in depth in his conversations with Engelmann, Wittgenstein had, during the time they had spent apart, concluded that this approach should in fact be discarded: the notion of transcendental willing subject has ended up 'falling apart in his hands'. ${ }^{13}$ I therefore propose that, by the winter of $1917-1918$, when Wittgenstein is

12 These letters are cited in Monk, R. Ludwig Wittgenstein: The Duty of Genius (New York: Penguin Books, 1991) 152-153.

13 I am borrowing this expression from Warren Goldfarb and Peter Sullivan - Goldfarb, W. 'Metaphysics as Nonsense: On Cora Diamond's The Realistic Spirit', Journal of Philosophical Research, 52, 57-73 (1997), 71; Sullivan, P. “"The General Propositional Form is a Variable.” (Tractatus 4.53)', Mind 113, 449, 43-56 (2004), 43. 
writing the remarks that would come to form the Prototractatus, he has already abandoned the Schopenhauerian notion of transcendental willing subject as condition of representation, religiousness and ethics. This would indeed explain why there is no mention of the willing subject in the Prototractatus, the Tractatus or indeed the Notebooks, after the $19^{\text {th }}$ of November 1916.

In my view, the notion of 'metaphysical subject' that emerges in the Tractatus' discussion of solipsism (in the TLP 5.6ff) is different from the notion of 'willing subject' from the Notebooks. The metaphysical subject at the heart of the solipsism discussion is not a transcendental condition of ethics, religiousness or, indeed, of representation; I defend this view elsewhere. ${ }^{14}$ We must therefore find a way of accounting for the religious and ethical dimension of the Tractatus that does not present Wittgenstein as endorsing this notion of willing subject as transcendental condition.

\section{The Purpose of the Tractatus ${ }^{15}$}

\section{a) The ethical point of the Tractatus}

There is no doubt that Wittgenstein regards the Tractatus as having an important ethical or religious dimension. This emerges most clearly in his 1919 letter to Ludwig Ficker, where Wittgenstein writes that 'the point of the book is an ethical'. ${ }^{16}$ In this letter, he

14 Tejedor, C. 'Solipsism in the Tractatus', Sentido y sinsentido: Wittgenstein y la crítica del lenguaje, ed. C. Moya, (Valencia: Pre-Textos, 2008) and Tejedor, C. (Forthcoming) An End to Philosophy: Language, Metaphysics and Value in Wittgenstein's Philosophy.

15 On this, see also Kremer, M. 'The Purpose of Tractarian Nonsense', Noûs 35, 39-73 (2001).

16 Letter cited in McGuinness op. cit. note 11, ch. 9. Some commentators have argued that Wittgenstein may be merely trying to entice a reluctant publisher by presenting his book as having an 
which indicates both that the Tractatus has an ethical purpose and that this purpose can only be fulfilled by being silent about ethics. This notion of silence in ethics emerges once again in the main text of the Tractatus (TLP 6.42, TLP 6.421).

The claim that ethics cannot be put into words gives rise to an obvious tension, however - one that lies at the very heart of the Tractatus. For, if ethics cannot be put into words, if there can be no 'propositions of ethics', how can a book - something that is, on the face of it, made up of words - have an ethical dimension? Part of my aim in what follows is to defend a new approach to this fundamental question of Tractarian scholarship.

\section{b) Clarifying formal concepts}

Wittgenstein's approach to religion and ethics in the Tractatus is intimately connected to what he regards as the central aim of his book. I suggest that the Tractatus aims, first and foremost, at the clarification of certain formal concepts, concepts such as those of proposition and thought. ${ }^{17}$ Clarifying formal concepts involves fine-tuning our practical abilities in relation to the use of signs. For instance, clarifying the formal concept of proposition involves fine-tuning our practical abilities relating to the use of linguistic signs to form senseful and senseless propositions. For Wittgenstein, it is very important that this process should involve the fine-tuning of practical abilities (of skills) we already

ethical point. In my view, however, Wittgenstein's insistence on the ethical dimension of the Tractatus needs to be taken seriously. On this, see Glock, H-J, A Wittgenstein Dictionary (Oxford: Blackwell, 1996) 330 and Tejedor (Forthcoming) op. cit, note 14.

17 I develop this further in Tejedor (Forthcoming) op. cit, note 14. Although our views ultimately diverge, I am indebted to Marie McGinn's discussion of formal concepts for the genesis of my thoughts on this issue - McGinn, M. Elucidating the Tractatus: Wittgenstein's Early Philosophy of Logic and Language. (Oxford: Oxford University Press, 2006) ch 7. 
possess. In this respect, the process of conceptual clarification in which the Tractatus engages us aims at drawing our attention to our pre-existing, pre-theoretical linguistic and thinking practices - to the way in which we use signs ordinarily, when we are outside the distorting context of traditional philosophical enquiry.

For Wittgenstein, the exercise of those practical abilities involved in the mastery of formal concepts - i.e. our use of signs - is ineffable: it is not describable by, reducible to, translatable into or capturable by propositions, thoughts or, indeed, pictures of any kind. To say something is to use facts of a certain kind (i.e. propositional signs) to represent other possible states: but this use - the use that turns factive propositional signs into factive propositions (i.e. into linguistic representations) - is not itself factive. ${ }^{18}$ Here, in my view, lies the crux of Wittgenstein's saying-showing distinction: our use of a sign shows what symbol the sign expresses and our mastery of the related formal concept is shown in our use of such a sign. This emerges in many different entries from the Tractatus, notably in TLP 4.1212, TLP 3.262, TLP 4.126, TLP 3.326 and TLP 3.327.

Wittgenstein suggests that our mastery of the formal concept of proposition - that is, the mastery demonstrated in the use we make of propositional signs to express propositions - is ineffable: it manifests itself in our use of propositional signs, but it cannot itself be described by means of propositions. This is an idea we will return to below.

c) Contingency, necessity and the sense of absolute control

18 As we will see below, propositions, like thoughts, are representing facts for Wittgenstein (TLP $3.14 \& T L P 3.12)$ 
For Wittgenstein, the process in which the Tractatus engages us aims at the clarification of formal concepts, notably those of proposition, thought and picture. In particular, this process, when successful, culminates in our coming to use signs - linguistic, psychical or iconic - in such a way as to reflect that there is no necessity outside logic (TLP 6.37). More specifically, this process culminates in a use signs that reflects that:

a) The world is fundamentally contingent

b) The notion of causal necessity is nonsensical

c) The notion that human beings are in absolute control of certain facts (i.e. in the kind of control that implies causal necessity) is nonsensical

As we will see shortly, these three positions are intimately connected to each other, for Wittgenstein: treating the world as fundamentally contingent involves treating the notions of causal necessity and of absolute control as nonsensical. I will return to this below. Before I do so, however, I would like to address an initial objection that emerges at this point. ${ }^{19}$ The objection can be put as follows: why exactly should the acceptance of the view that the world is fundamentally contingent go hand in hand with a rejection of the notions of causal necessity and absolute control? After all, some have argued that the fundamental contingency of the world is in fact compatible with both causal necessity and with the notion of absolute control. Simone Weil, for instance, holds both that the world is fundamentally contingent and that it is governed by causal necessity. Indeed, the possibility of combining these two notions is central to her project of attempting to

19 I am grateful to Anthony O'Hear for his generous discussion of this objection. 
reconcile God as creator with the existence of suffering in the world. For Weil, the world is fundamentally contingent in that it could have failed to obtain, since the initial creation of the world is an exercise in God's freedom in love. In so far as the creation of the world results from God's absolute freedom, the world could not have obtained at all - it is in this respect that the world is fundamentally contingent, for Weil. Nevertheless, the world thus created is a world that is governed by causal necessity - and that must indeed be so if God's ontological independence is to be safeguarded. ${ }^{20}$

In Weil's view, there is no difficulty in claiming both that the world is fundamentally contingent and that it is governed by causal necessity. The question before us is therefore: why does Wittgenstein rule out this option? Why does he suggest that becoming clear about the fundamental contingency of the world involves rejecting causal necessity (and the associated notion of absolute control) as nonsensical?

The answer to this question lies in Wittgenstein's highly specific understanding of the notion of fundamental contingency and on the motivations that drive this understanding. Although this cannot be fully addressed in the space available, I will, in what follows, offer an initial approximation to it.

\section{d) Contingency: senseful propositions and possible states}

In order to understand Wittgenstein's rejection of causal necessity, it is important to revisit his approach to contingency, as it emerges in the treatment he gives to pictures and

20 Weil, S. Notebooks, II, (London: Routledge \& Kegan Paul, 1976) 402; Weil, S. Waiting for God, (New York: Perennial Classics, 2001) 99; Weil, S. Gravity and Grace, (London: Routledge, 2004) 32 - 33. 
possible states. Wittgenstein indicates that senseful propositions, thoughts and iconic representations are all pictures. Senseful propositions, like other pictures:

i) are either determinately true or determinately false [bivalence]

ii) are both capable of being true and capable of being false [bipolarity]

iii) are informative about the reality [informativeness]

iv) ultimately decompose into elementary propositions that are logically independent from each other [logical independence] and that are made up exclusively of simple names [simplicity of meaning]

Let us briefly consider iii) and iv). Senseful propositions purport to convey information about reality - information that may be unknown to some language speakers. Communicating new senses to each other is a central purpose - and part of the essence of senseful language. Indeed, the informativeness of a proposition goes hand in hand with its sensefulness. Propositions are informative in that they depict possible states of the world, possible ways in which reality might be; but that is precisely why they are senseful. The information conveyed by a senseful proposition may turn out to be false, if the depicted possible state does not obtain as a fact in reality. Nevertheless, the main purpose of senseful language is to be informative and speakers use senseful propositions to convey to others information that may be new to them.

It belongs to the essence of the proposition that it should be able to communicate a new sense to us. (TLP 4.027) 
In connection to this it is important to note that, according to Wittgenstein, the natural sciences aim to produce true informative senseful propositions. Natural scientists aim to produce contingently true, informative descriptions of the facts that make up reality: facts that could have happened not to obtain and that could be unknown to language speakers.

In spite of this aim, some of the propositions produced by the natural sciences are, of course, false. After all, sometimes the natural sciences get things wrong: sometimes they make mistakes and produce false descriptions of reality (as, for instance, with the pre-Copernican view that the sun revolves round the earth). Nevertheless, their aim (their purpose) is to produce propositions that are contingently true and therefore informative. It with this in mind that Wittgenstein writes, in the Tractatus:

The totality of true propositions is the whole of the natural sciences (or the whole corpus of the natural sciences). (TLP 4.11)

Contingently true senseful propositions are therefore central to Wittgenstein's understanding of the role of the natural sciences. The importance of this idea will become clear below.

Let us now consider iv), that is, the idea that elementary propositions are logically independent from each other. For Wittgenstein, elementary propositions are the logically most basic type of senseful proposition: elementary propositions cannot be analysed into further propositions and consist exclusively of simple names (TLP 4.21ff). Elementary propositions are logically independent from one another in that the truth-value of one 
elementary proposition cannot determine the truth-value of another. Non-elementary senseful propositions arise from the application of logical operations to elementary propositions; this is indeed why the former can be logically analysed into the latter. And the truth-value combinations of elementary propositions determine the truth-values of the resulting non-elementary propositions.

Wittgenstein indicates that senseful propositions depict possibilities, possible states of reality: elementary propositions depict states of affairs and non-elementary propositions depict more complex possible situations. Possible states (i.e. states of affairs and possible situations) are such that they:

$i^{*} \quad$ either determinately obtain or determinately fail to obtain

ii*) are both capable of obtaining and capable of failing to obtain

iii*) ultimately decompose into states of affairs that are logically independent from each other and that are exclusively made up of simple objects.

States of affairs are the logically most basic type of possible state. They are logically independent from each other in that the obtaining or non-obtaining of one state of affairs does not entail the obtaining or failing to obtain of another. For Wittgenstein, the logical independence of elementary propositions and that of states of affairs is a requirement of his commitment to the combinatorial nature of sense..$^{21}$

\section{e) Necessary truth and senseless propositions}

$21 \quad$ This has been insightfully discussed elsewhere, notably by Zalabardo - Zalabardo, J. L. 'The Tractatus on Logical Consequence', European Journal of Philosophy, 18, 3, 425-442 (2010) 431. 
One of the corollaries of the logical independence of states of affairs is that there can be no necessary connections between them: the obtaining of one state of affairs cannot necessitate the obtaining of another. This is reflected at the level of elementary propositions in that the truth of one elementary proposition cannot entail the truth of another. Necessary connections of entailment only arise at a higher level of complexity. The reason for this is that, according to Wittgenstein, it is only at this higher level of complexity that conceptual relations - that is, relations that can be transparently revealed through logical analysis - start to emerge. Imagine that a possible situation $A$ is analysable as the conjunction of the more basic possible situation $a$ and other possible situations. If so, $A$ will necessitate or entail $a$ by virtue of the conceptual relations between them. And this will be reflected in the non-elementary propositions that represent $A$ and $a$ - let us call these propositions 'A' and 'a', for the sake of simplicity. Imagine, for instance, that the propositions in question are 'John is a bachelor' ('A') and 'John is unmarried' ('a'). The proposition 'John is a bachelor' entails the proposition 'John is unmarried' by virtue of the conceptual connections between the two since 'John is a bachelor' is analysable into the conjunction of 'John is unmarried' and other propositions. This relation of entailment can me made evident through the use of truthtables, in particular, by constructing the truth-table for the further proposition 'If John is a bachelor, John is unmarried'. Such a truth-table would show this further proposition to be a tautology, thereby revealing the connection between 'John is a bachelor' and 'John is unmarried'. 
In the Tractatus, Wittgenstein distinguishes between senseful propositions and senseless propositions such as necessarily true tautologies and necessarily false contradictions (TLP 4.46). Since elementary propositions are logically independent from each other, senseless tautologies and contradictions only arise at a higher level of complexity, when a sufficient number of logical operations have been applied to elementary propositions for conceptual relations to arise. For Wittgenstein, senseless propositions are a corollary of senseful language. They are senseless rather than nonsensical in that they result from applying logical operations to senseful propositions. In this respect, senseless propositions are, like senseful propositions, 'part of the symbolism' (TLP 4.4611). Unlike senseful propositions, however, the purpose of senseless propositions is not to convey information about reality: senseless propositions do not depict possible states of the world, they say nothing (and purport to say nothing) about the state of reality. Senseless propositions are altogether uninformative about reality - this is indeed why they are senseless.

Tautologies and contradictions lack sense. [...]

(For example, I know nothing about the weather when I know that it is either raining or not raining.) (TLP 4.461)

\section{$\underline{\text { 3. Wittgenstein's Rejection of Causal Necessity }}$}

Having revisited Wittgenstein's notions of contingency and necessity, through our discussion of senseful propositions, possible states and senseless propositions, we are 
now in a position to explain why rejecting the notion of causal necessity as nonsensical goes hand in hand with being clear about the fundamental contingency of the world. I will begin this section with a brief overview of the Causal Necessity View and will then present two sets of considerations that expose this view as nonsensical, according to Wittgenstein.

\section{a) The Causal Necessity View}

The Causal Necessity View rejected by Wittgenstein suggests that facts (elements of reality) can be necessarily connected to each other, not by virtue of conceptual relations between them, but by virtue of certain laws of nature governing reality. Imagine that $A$ is an obtaining possible state, a fact; and imagine further that $A$ causes possible state $C$ also to obtain as a fact. Advocates of the Causal Necessity View would argue that, if $A$ really is the cause of $C$, then $A$ necessitates or entails $C$. However, this necessary connection, this relation of entailment, is not, in their view, one that arises by virtue of the conceptual relations between $A$ and $C$. Imagine, for instance, that the presence of a flame (under certain specified circumstances) causes a piece of wax to melt. In other words, imagine that there is a genuine causal relation between these two obtaining possible states. Advocates of the Causal Necessity View would suggest that, in this scenario, the presence of the flame (under the specified circumstances) necessitates or entails the melting of the wax. In their view, however, this necessary relation of entailment arises, not by virtue of any conceptual relations between the two possible states, but by virtue of something else - namely, by virtue of the fact that certain laws of nature govern reality. 
According to Wittgenstein, this position betrays a number of fundamental confusions and misunderstandings, as we will now see.

\section{b) No necessity outside logic}

For Wittgenstein, being clear about the formal concepts of senseful proposition and of possible state involves treating signs in such a way as to reflect i) - iv). Furthermore, it involves treating signs in such a way as to reflect that necessary relations of entailment between propositions (or between possible states) arise only by virtue of conceptual relations between them - relations that do not emerge at the level of elementary propositions and states of affairs. Advocates of the Causal Necessity View, in contrast, do not use signs in this way: their use of signs suggests that there can be necessary connections between propositions (or between possible states) that are not conceptual in nature, thereby opening the way for such connections to arise at any level complexity (including at that of elementary propositions and states of affairs). But this, for Wittgenstein, betrays a fundamental lack of clarity as to what it is for something to be a senseful proposition or a possible state in the first place: it betrays a lack of mastery in certain key formal concepts. For, given Wittgenstein's approach to the combinatorial nature of sense, necessary relations of entailment can only arises from conceptual, logical relations: there is no necessity outside logic (TLP 6.37). ${ }^{22}$

\footnotetext{
22 Note indeed that Wittgenstein's use of truth tables to reveal the combinatorial nature of sense and his view that truth tables render the signs for logical connectives superfluous is incompatible with the Causal Necessity View. For his whole approach is predicated on the idea that only propositions connected to each other by virtue of conceptual relations (i.e. by virtue of relations that can be transparently revealed through logical analysis) can entail each other. Wittgenstein's rejection of causal necessity therefore runs very deep and permeates his entire position in the Tractatus.
} 
In addition, the Causal Necessity View also betrays a more basic misunderstanding concerning the notions of contingency and necessity. For Wittgenstein, both contingency and necessity are purely logical notions in that they are both characterised by a particular type of independence. ${ }^{23}$ Consider contingency first. For Wittgenstein, it is crucial that the contingency of possible states and the contingency of propositions should be independent from reality. More specifically, whether a possible state satisfies $\left.\mathrm{i}^{*}\right)$ - iii*) cannot itself be dependent on whether a certain other state obtains (or fails to obtain) as a matter of fact, in reality. A state only counts as contingent in the required respect when its satisfying $\left.\mathrm{i}^{*}\right)$ - $\mathrm{iii}^{*}$ ) is guaranteed independently of what happens to obtain in reality (of the facts). Similarly, that propositions satisfy i) - iv) and thereby possess a sense is guaranteed independently of the facts and, therefore, of the truth of any other propositions. This, in Wittgenstein's view, is a requirement of the very possibility of sense, as is made clear in his discussion of simples: ${ }^{24}$

If the world had no substance [i.e. if logical analysis did not ultimately reveal simples], then whether a proposition had sense would depend on whether another proposition was true. (TLP 2.0211)

In that case we could not sketch any picture of the world (true or false). (TLP 2.0212)

\footnotetext{
23 There are other respects in which contingency and necessity are 'purely logical' for Wittgenstein, but it is this notion of independence from reality that is crucial for our purposes.

24 Glock op. cit. note 16, 269-274 and Tejedor, C. 'Sense and Simplicity: Wittgenstein's Argument for Simple Objects', Ratio (new series) XVI, 272-289 (2003).
} 
In the above entries, Wittgenstein indicates that, if the sensefulness of a proposition ('whether a proposition had sense' - TLP 2.0211) were dependent on the truth of another, there would be no senseful language and, indeed, no senseful pictures of any sort ('we could not sketch any picture of the world' - TLP 2.0212). The contingency of states (and, correspondingly, the contingency and sense of propositions) is guaranteed from a purely logical point of view, independently of which propositions are true and which facts happen to obtain in reality. Recognising this is part and parcel of recognising what it is for a proposition to be senseful and recognising a proposition as senseful is recognising that it is contingent in this particular way.

Necessity too, for Wittgenstein, involves a particular type of independence from what happens to obtain, as a fact, in reality. This emerges with particular force in his discussion of senseless tautologies, where it is made clear that regarding a tautology as necessarily true involves regarding it as true independently of what may happen to obtain, in reality $(T L P 4.6,4.461,4.463) .^{25}$

At the very heart of Wittgenstein's position is therefore the idea that both contingency and necessity are guaranteed independently of what happens to obtain, as a matter of fact, in reality. The Causal Necessity View, in contrast, runs directly counter this view. For it suggests that causes guarantee (i.e. necessitate) their effects by virtue of the fact that certain laws govern reality. For Wittgenstein, this is a hybrid and fundamentally ill-conceived notion. It is a hybrid notion in that it attempts to ally together the idea of something being guaranteed with the idea of that guarantee stemming from a contingent fact. But, in Wittgenstein's view, pace his discussion of simples, a contingent

$25 \quad$ Glock op. cit. note $16,198-202$ 
fact (e.g. that certain laws of nature are at work) cannot offer the required guarantee. And being clear about the formal concepts of senseful proposition, possible state and senseless proposition involves treating this notion of a contingency-based guarantee as nonsensical.

\section{c) Causation and the natural sciences}

This leads us to a further problem with the Causal Necessity View, one concerning the role played by causation in the natural sciences. In TLP $6.36-6.362$, Wittgenstein acknowledges that causation is at the very heart of our understanding of the natural sciences. Indeed, one of the central purposes of the natural sciences is to informatively and accurately describe the causal relations that hold between facts. But, for Wittgenstein, a proposition is only informative when it is senseful, that is, when it is contingent (in the sense of satisfying $\mathrm{i}-\mathrm{iv}$ ). Since necessary truth, for Wittgenstein, is the mark of senselessness and therefore of uninformativeness, a scientific description of a certain causal chain cannot be both informative and necessarily true. In this respect, the Causal Necessity View fundamentally distorts the role played by causal descriptions in the natural sciences

For Wittgenstein, the notion of causal necessity is a particularly damaging philosophical construct (TLP 5.136-5.1362). Falling prey to the illusion of causal necessity involves acting as if propositions that are not connected to each other by means of conceptual relations of logical entailment are nevertheless necessarily connected to each other in some other - 'causal' - way. Wittgenstein is not, in the Tractatus, hostile to the idea that causal relations might hold between facts. There is, indeed, in his view, a 
viable understanding of causation (cf. TLP 6.321, TLP 6.36). However, this understanding of causation does not include the Causal Necessity View: causation, properly understood, does not involve necessary connections between facts (TLP 5.136 $5.1362){ }^{26}$

d) Wittgenstein's rejection of the notion of absolute control

As we have just seen, the notion of causal - or material - necessity is a piece of philosophical nonsense, in Wittgenstein's view. For him, the process of conceptual clarification of the Tractatus culminates, when successful, in a use of signs that reflects that there are no necessary relations between facts other than conceptual relations. When successful, this process therefore enables us not to fall prey to this particular type of philosophical nonsense.

And this, in turn, involves shedding a particular understanding of ourselves as being in absolute control of certain aspects of the world. For the notion of absolute control - of being able causally to guarantee the obtaining or non-obtaining of certain facts - is fuelled by that of causal necessity. So much so that the misconceived sense of being in absolute control vanishes when we recognise the notion of causal necessity as nonsensical: when we come to 'see the world aright' (TLP 6.54). Our sense of being in absolute control vanishes when the process of conceptual clarification of the Tractatus succeeds in fine-tuning our linguistic and thinking abilities, so that our use of signs comes to reflect the fundamental contingency of facts.

26 For further details, see Tejedor (Forthcoming) op. cit, note 14. 
In Wittgenstein's view, therefore, the process of conceptual clarification of the Tractatus results, when successful, in our coming to recognise as nonsensical both the notion of causal necessity and the related notion that we - human beings - are in absolute (i.e. causally necessitating) control of certain aspects of the world.

There is no compulsion making one thing happen because another has happened. The only necessity that exists is logical necessity. (TLP 6.37)

\section{An Ethics of Conceptual Clarity}

\section{a) Facts, contingency and ethics}

According to Wittgenstein, obtaining possible states, pictures, propositions, thoughts and, indeed, empirical selves and minds (consisting of logical arrangements of thoughts) are all facts (TLP 2, TLP 2.141, TLP 3, TLP 3.14, TLP 5.542, TLP 5.5421). And all facts (be they representing facts, such as propositions and thoughts, or represented facts, such as obtaining possible states) are fundamentally contingent. Propositions, thoughts and generally pictures are contingent in that they satisfy i) - iv); in turn, possible states are contingent in that they satisfy i) - iii). In addition, all facts are fundamentally contingent in that there are no necessary relations of entailment other than those arising from conceptual or logical relations. For Wittgenstein, being clear as to the fundamental contingency of facts involves using signs in such a way as to reflect this fundamental 
contingency. But what, precisely, is the connection between this kind of conceptual clarity and ethics?

Wittgenstein suggests that, given the fundamental contingency of facts, it is a source of profound wonder that any possible state should obtain as a fact. This sense of wonder arises in connection to all facts: physical facts (involving the rocks, plants, animals and human physical bodies we describe in language and think about) but also mental facts (i.e. our thoughts, desires, beliefs, emotions and, more broadly, our minds and empirical selves). Being clear in one's grasp of certain formal concepts involves being disposed to use signs in particular ways so as to reflect the fundamental contingency of facts. But this involves treating ourselves (i.e. human beings) as facts on a par, with respect to their contingency, with all other facts in the world. For Wittgenstein, using signs in such a way as to reflect that we (empirical selves) are exactly on a par with all other facts in the world is displaying a religious attitude to the world. So being conceptually clear - in particular, avoiding the illusion of absolute control - is having a religious or ethical attitude of wonder at the fundamental contingency of the world.

\section{b) A non-emotive, dispositional religious attitude}

For Wittgenstein, using signs in such a way as to reflect the fundamental contingency of facts is displaying a religious, ethically correct attitude to the world. But how exactly are we to understand this notion of religious attitude? Here, it is important to emphasise that, for Wittgenstein, the religious or ethical attitude is not an emotive attitude: the ethicoreligious attitude does not involve experiencing certain emotive responses to the world. 
Note indeed that emotions are describable mental facts - facts that are on a par with all other facts in the world. That mental facts have no ethical currency is made clear in the following passage from 'A Lecture on Ethics':

But what I mean is that a state of mind, so far as we mean by that a fact which we can describe, is in no ethical sense good or bad. If for instance in our world-book we read the description of a murder [...]. Certainly the reading of this description might cause us pain or rage or any other emotion, or we might read about the pain or rage caused by this murder in other people when they heard of it, but there will simply be facts, facts, and facts but no Ethics. [My italics] (LOE, 11)

The religious or ethical attitude is not a form of emotive response. For emotions are mental facts that have, in and of themselves, no ethical dimension: mental facts are ethically neutral. ${ }^{27}$ Instead, I suggest that the religious or ethical attitude is dispositional, for Wittgenstein: it is the disposition to use signs in such a way as to reflect the fundamental contingency of all facts. Having a religious or ethical attitude to the world is being clear about certain formal concepts, it is having certain practical abilities honed in, so as to be disposed to use signs in particular ways. Being in such a state of conceptual clarity might cause one to experience certain emotions, but these emotions, in and of themselves, do not constitute the ethical attitude. These emotions are epiphenomenal to the ethico-religious attitude: they are phenomena that tend to accompany the attitude (at

\footnotetext{
27 In particular, the religious attitude is not the type of emotive attitude characterised by the abandoning or letting go of desire. For desire ('the empirical will that is of interest only to psychology' $T L P$ 6.423) is also factive for Wittgenstein, and, therefore, in and of itself, devoid of either positive or negative ethical value. Note indeed that both pursuing desire and attempting to let go of desire can be done out of an illusory sense of absolute control and therefore be unethical.
} 
least in Wittgenstein's own personal case, as he attests to in LOE 8), but they are neither constitutive, nor in any way necessary to the attitude..$^{28}$

\section{$\underline{\text { 5. Ineffability and the status of religious pseudo-propositions }}$}

In this final section, I would like to explore in more detail Wittgenstein's notion of religious or ethical ineffability and the status he ascribes to religious and ethical pseudopropositions.

\section{a) Ineffability and ethics}

In 'A Lecture on Ethics', Wittgenstein explicitly acknowledges that religious or ethical propositions - that is, sentences used with the purpose of trying to express religious or ethical insights - are nonsensical ( $\operatorname{LOE} 8$ ). The question before us at this point is therefore: are such propositions nevertheless expressive of ethical insights? More specifically: are such propositions, in spite of their nonsense, adequate vehicles for the expression of the ethico-religious attitude, in Wittgenstein's view? I suggest that they are not. For, as we saw above, the religious or ethical attitude is precisely one of conceptual clarity; and attempting to express or communicate such conceptual clarity through a nonsensical - that is a conceptually confused - use of signs has to be self-defeating. Indeed, a nonsensical use of signs is usually the symptom of conceptual confusion - not the mark of conceptual clarity. And nonsense tends to breed further nonsense; this is

28 I am on this point indebted to Severin Schroeder's intriguing discussion of Wittgenstein's later approach to religiousness - Schroeder op. cit. note 1, 456. 
indeed why it is so pernicious, according to Wittgenstein. Nonsensical - conceptually confused - ethical or religious propositions cannot be regarded as vehicles for the expression of conceptual clarity: they are not conveyors of - or even adequate markers for - the ethical or religious attitude. ${ }^{29}$

For Wittgenstein, the ethico-religious attitude is a disposition to use signs in such a way as to reflect the fundamental contingency of facts: it is a disposition to use signs in way that demonstrates one's mastery of - one's clarity in - certain formal concepts. We demonstrate our mastery of formal concepts whenever we use signs to express senseful propositions and whenever we refrain from using signs to produce nonsense. In this respect, it could perhaps be argued that senseful language - senseful language as a whole - might be an adequate vehicle for the expression of the ethico-religious attitude. If nonsense is incapable of expressing the ethico-religious attitude, perhaps senseful language - language in its entirety - can. Interestingly, Wittgenstein considers and then rejects this very idea in 'A Lecture on Ethics':

Now I am tempted to say that the right expression in language for the miracle of the existence of the world, though it is not any proposition in language, is the existence of language itself. But what then does it mean to be aware of this miracle at some times and not at other times? For all I have said by shifting the expression of the miraculous from an expression by means of language to the expression by the existence of language, all I have said is again that we cannot express what we want

\footnotetext{
29 In this respect, they do not have the kind of relation to the attitude in question that sentences might bear to the emotions they express: emotive sentences can be viewed as expressing emotions without distorting them in this fundamental way.
} 
to express and that all we say about the absolute miraculous remains nonsense. [...] I see now that these nonsensical expressions were not nonsensical because I had not yet found the correct expressions, but that their nonsensicality was their very essence. (LOE 11)

Senseful language cannot be regarded as a marker for the ethical attitude in that senseful language as a whole - the totality of senseful propositions - fails to pick out anything in particular. But this simply goes to show that the ethical attitude cannot be conveyed in language in any way. Ultimately, for Wittgenstein, the reason for this is that approaching something (here a certain attitude) as if it could be conveyed in language (if only we could find 'the correct expressions'), is already treating it as non-ethical. Approaching something as if it can be conveyed in language is already treating it from the perspective of the natural sciences, rather than that of ethics. This emerges clearly in Wittgenstein's discussion of the notion of a miracle, in 'A Lecture on Ethics' (LOE 10).

Language - whether senseful language as a whole or nonsensical propositions - is incapable of conveying the ethico-religious attitude. The problem is not merely that propositions - senseful or nonsensical - cannot say or express such an attitude; the problem is that presenting such an attitude as if it could be conveyed in language (if only we could find 'the correct expressions' - LOE 11) fundamentally distorts its ethical nature. For approaching something as if it can conveyed in language is already approaching it in a factive, non-ethical manner. 


\section{b) The status of the ethical pseudo-propositions of the Tractatus}

As we have just seen, religious or ethical propositions - that is, sentences used with the purpose of attempting to express religious or ethical insights - are nonsensical. Indeed any attempt to express ethico-religious insights through language automatically distorts such insights and is self-defeating. Given this, Wittgenstein's decision to include, in the TLP 6.4ff, a series of ethico-religious propositions may seem deeply puzzling. What, we may ask, is the role played by these propositions in the Tractatus? What role does Wittgenstein intend them to play?

In my view, Wittgenstein cannot have regarded these nonsensical propositions as responsible for capturing and expressing any ethical insights yielded by the Tractatus. The Tractatus has an ethical purpose, not because it contains, in the TLP 6.4ff, a series of propositions that express ethical insights in spite of their nonsensicality, but because the book - as a whole - enables us to hone in our mastery of certain formal concepts. The process of conceptual clarification in which the Tractatus engages us leads us, when successful, to using signs in such a way as to reflect the fundamental contingency of facts; and since the ethico-religious attitude is precisely the disposition to use signs this way, successfully engaging in this process is, in and of itself, undergoing a powerful ethical transformation, in Wittgenstein's view.

The question of how, according to Wittgenstein, the Tractatus succeeds in delivering this process of conceptual clarification is a complex one that cannot, for reasons of space, be addressed here. ${ }^{30}$ It is worth noting, however, that part of the method

$30 \quad$ I discuss this in Tejedor (Forthcoming) op. cit, note 14. 
of the Tractatus involves reminding us that any given arrangement of signs can be used in different ways to produce senseful, senseless and nonsensical propositions. In this respect, I suggest that the sentences in the TLP 6.4ff are put to us so that we exercise our linguistic muscles (our practical linguistic abilities) against them. Note indeed that these sentences can be read in different ways. Consider for instance the claim, in TLP 6.431, that 'at death the world [...] comes to an end'. If we read this as an attempt to comment on the death of the transcendental willing subject, the proposition thus expressed is nonsensical, since the notion of willing subject is plain nonsense Wittgenstein. If, in contrast, we read the sentence as asserting that the physical world ended with the death of some particular empirical self, the sentence expresses a contingently false senseful proposition. The point here is that a sentence such as 'at death the world [...] comes to an end' (TLP 6.431) can be read in a myriad of ways; but what we learn, by considering different readings - different uses - of this sentence, is that none of them genuinely preserves the apparent ethical dimension of the sentence. When the sentence is interpreted in a way that renders it nonsensical, any purported ethical insight falls a part in our hands; when it is interpreted in a way that renders it senseful, it becomes factive and altogether loses its ethical edge. ${ }^{31}$ This is just as it should be since, for Wittgenstein, ethical insights are, by their very nature, not to be expressed in language. It is in this respect that:

All propositions are of equal value. (TLP 6.4)

$31 \quad$ Sentences also lose any purported ethical edge when they are used to express senseless tautologies and contradictions, as I discuss in Tejedor (Forthcoming) op. cit, note 14. 


\section{Conclusion}

We have seen that, for Wittgenstein, having a religious attitude - that is, being in a good ethical state - is being conceptually clear. Being clear about certain formal concepts (such as those of picture, proposition and thought) is being disposed to treat all facts as fundamentally contingent. For this reason, the clarificatory purpose of the Tractatus is its ethical purpose: the two are one and the same. In Wittgenstein's view, if the Tractatus succeeds in fulfilling its ethical purpose, it does so in that it enables us to fine-tune our

practical abilities in the use of signs: it enables us to become clear in our mastery of formal concepts.

Chon Tejedor

Regent's Park College, University of Oxford

Email: ctejedor@mac.com 